\title{
Critérios para a seleção do sistema de retenção na reabilitação protética sobre implantes: próteses parafusadas versus cimentadas
}

\author{
Criteria for the selection of the retention system in prosthetic \\ rehabilitation on dental implants: screwed versus cemented prosthesis
}

\author{
Criterios para la selección del sistema de retención en la rehabilitación \\ protetica sobre implantes: prótesis parafusadas versus cimentadas \\ Ricardo Alexandre ZAVANELLI ${ }^{1}$ \\ Adriana Cristina ZAVANELLI ${ }^{2}$ \\ Lauanne Andressa Silva SANTOS 3 \\ Jaqueline Barbosa Magalhães ZAVANELLI \\ ${ }^{1}$ Prof. Associado da Disciplina de Prótese Dentária do Departamento de Reabilitação Oral, Faculdade de Odontologia FO, UFG \\ Univ. Federal de Goiás, 74605-020 Goiânia- GO, Brasil \\ ${ }_{2}^{2}$ Prof. Doutora da Disciplina de Prótese Parcial Fixa do Departamento de Materiais Odontológicos e Prótese, \\ Faculdade de Odontologia de Araçatuba FOA, Unesp. Univ. Estadual Paulista, 14801-903 Araçatuba - SP, Brasil \\ ${ }^{3}$ Discente do Curso de Odontologia, FO Faculdade de Odontologia, UFG Univ. Federal de Goiás, \\ 74605-020 Goiânia- GO, Brasil. \\ ${ }^{4}$ Especialista em Endodontia e Implantodontia
}

\begin{abstract}
Resumo
Introdução: Na reabilitação sobre implantes, a união entre a peça protética e o pilar e/ou diretamente com o implante pode ocorrer por cimentação ou por parafusamento. Contudo, esta escolha pode se tornar desafiadora em determinadas situações e deve ser criteriosamente considerada ainda na etapa de planejamento, previamente a instalação dos implantes, maximizando assim a previsibilidade do resultado final e, consequentemente, o sucesso do tratamento. Objetivo: Apresentar e discutir as informações obtidas na literatura quanto às vantagens, desvantagens, critérios de seleção, indicações e contraindicações dos sistemas de retenção por cimento e por parafuso nas próteses sobre implantes, exemplificando variadas situações clínicas e a aplicabilidade das informações aqui fornecidas; com o intuito de fornecer respaldo ao cirurgião-dentista para uma seleção ideal e segura nos mais diversos casos. Conclusão: Conclui-se que não existe um método soberano ou protocolo fixo na escolha entre prótese cimentada ou parafusada e a predileção do profissional acaba por ser o fator determinante. Cabe ao profissional, experiência e bom senso para pontuar fatores preponderantes na reabilitação em questão e então eleger o sistema de retenção que melhor atende suas expectativas. Descritores: Reabilitação Bucal; Próteses e Implantes; Implantes Dentários.
\end{abstract}

\begin{abstract}
Introduction: In implant rehabilitation, the union between the prosthetic part and the abutment and or directly with the implant can occur by cementation or by screwing. However, this choice may become challenging in certain situations and should be carefully considered in the planning stage, prior to implant installation, thus maximizing the predictability of the final result and consequently the success of the treatment. Objective: Present and discuss the information obtained in the literature regarding the advantages, disadvantages, selection criteria, indications and contraindications of cemented and screwed retention systems in implants, exemplifying with a variety of clinical situations and the applicability of the information here provided; with the purpose of providing support to the dentist for an ideal and safe selection in the most diverse cases. Conclusion: It is concluded that there is no sovereign method or fixed protocol in the choice between cemented or screwed prosthesis and the professional's predilection turns out to be the determining factor. It is up to the professional experience and common sense to punctuate preponderant factors in the rehabilitation and then elect the retention system that best suits your expectations.

Descriptors: Mouth Rehabilitation; Prostheses and Implants; Dental Implants.
\end{abstract}

\section{Resumen}

Introducción: En la rehabilitación sobre implantes, la unión entre la pieza protética y el pilar y / o directamente con el implante puede ocurrir por cementación o por atornillado. Sin embargo, esta elección puede ser desafiante en determinadas situaciones y debe considerarse cuidadosamente en la etapa de planificación, previamente la instalación de los implantes, maximizando así la previsibilidad del resultado final y, consecuentemente, el éxito del tratamiento. Objetivo: Presentar y discutir las informaciones obtenidas en la literatura en cuanto a las ventajas, desventajas, criterios de selección, indicaciones y contraindicaciones de los sistemas de retención por cemento y por tornillo en las prótesis sobre implantes, ejemplificando variadas situaciones clínicas y la aplicabilidad de las informaciones aquí suministradas; con el propósito de proporcionar respaldo al cirujano-dentista para una selección ideal y segura en los más diversos casos. Conclusión: Se concluye que no existe un método soberano o protocolo fijo en la elección entre prótesis cementada o atornillada y la predilección del profesional termina siendo el factor determinante. Cabe al profesional, experiencia y buen sentido para puntuar factores preponderantes en la rehabilitación en cuestión y luego elegir el sistema de retención que mejor atiende sus expectativas.

Descriptores: Rehabilitación Bucal; Prótesis e Implantes; Implantes Dentales.

\section{INTRODUÇÃO}

A reabilitação oral através do uso de implantes dentários é considerada previsível, eficaz e segura em relação aos tratamentos protéticos convencionais. Os implantes dentários podem ser indicados aos pacientes desdentados totais ou parciais e, para ambos, é capaz de restabelecer a função mastigatória, fonética e estética de forma semelhante à dentição natural e, principalmente, preservando os elementos dentários remanescentes ${ }^{1}$.

Contudo, paralelo ao crescente uso dos implantes osseointegráveis, sua aplicação se tornou dificultada em determinadas situações seja por limitações estéticas ou pelas limitações mecânicas inerentes a determinados componentes das próteses sobre implantes ${ }^{2}$. O desafio de se utilizar a ancoragem de implantes no suporte de próteses induziu ao questionamento à cerca dos materiais e das técnicas utilizadas. Um destes questionamentos relaciona-se com a escolha do sistema de retenção da prótese sobre implante confeccionada diretamente sobre o implante ou sobre o pilar intermediário: cimentar ou parafusar ${ }^{3}$ ?

$\mathrm{Na}$ reabilitação sobre implantes, a fixação da peça 
protética feita direta sobre o implante ou sobre o pilar intermediário pode ocorrer por meio do parafusamento ou cimentação, o que gera dúvida aos profissionais entre qual caminho seguir ${ }^{4}$. Neste cenário, não há um posicionamento fechado ou pré-determinado de parafusar ou cimentar, cabendo ao reabilitador avaliar o melhor meio de fixação da prótese sobre implante 3 .

O sistema de fixação por parafusamento foi o primeiro a ser utilizado, desde 1965 , quando o protocolo clássico foi descrito por Branemark, apresentando histórico bem documentado e elevadas taxas de sucesso ${ }^{5}$. Porém, ainda que as próteses parafusadas sejam as mais utilizadas, considerando principalmente a reversibilidade do tratamento, a retenção por cimento vem ganhando cada vez mais popularidade entre os profissionais, haja vista que a cimentação remete aos conceitos tradicionais das próteses fixas sobre dentes e esse fato gera um conforto aos profissionais por já dominarem o procedimento de cimentação ${ }^{6}$.

Apesar da escolha entre próteses cimentadas ou parafusadas estar majoritariamente associada à preferência pessoal do profissional; aspectos importantes devem ser considerados para uma seleção ideal, tais como: adaptação marginal, retenção, oclusão, estética, instalação/cimentação, reavaliação, reversibilidade do caso, posicionamento do implante, tipo de conexão protética e longevidade ${ }^{7}$.

É importante ainda que, objetivando alcançar o sucesso em longo prazo da reabilitação, a escolha do sistema de retenção da prótese sobre implantes seja criteriosamente considerada ainda na etapa de planejamento, previamente a instalação dos implantes, maximizando assim a previsibilidade do resultado final ${ }^{8}$.

Com o intuito de fornecer respaldo ao cirurgiãodentista para uma seleção proteticamente ideal e segura nos casos de reabilitação sobre implantes, o objetivo deste estudo foi de apresentar e discutir as informações obtidas na literatura quanto às vantagens, desvantagens, critérios de seleção, indicações e contraindicações dos sistemas de retenção por cimento e por parafuso, exemplificando variadas situações clínicas.

\section{REVISÃO DA LITERATURA}

O método de fixação ideal da peça protética ao pilar do implante seria aquele que viabilizasse um assentamento mais passivo possível proporcionando otimização da direção das cargas; aprimoramento estético, acesso facilitado ao procedimento de provas, redução drástica da perda da crista óssea, além de atenuar complicações, custo e tempo operatório 9 . Freitas et al. ${ }^{7}$ pontuaram a importância de se ter em mente a inexistência de um método soberano uma vez que todos têm suas vantagens e desvantagens quando aplicados a particularidade de cada situação clínica e afirmaram que aspectos importantes devem ser considerados nesta decisão como adaptação marginal, retenção, oclusão, estética, instalação/cimentação, reversibilidade do caso e longevidade (fratura dos materiais restauradores e fadiga dos componentes protéticos).

A seleção do sistema de retenção entre prótese parafusada ou cimentada requer alguns apontamentos, sendo o tipo de conexão protética possivelmente o mais relevante deles, ilustrado na Figura $1^{10}$. Nas conexões hexagonais tipo Hexágono Externo (HE) ou Hexágono Interno (HI), as tensões promovidas pela carga oclusal são transferidas diretamente aos parafusos de fixação, enquanto que nas conexões internas tipo Cone Morse (CM) estas tensões são distribuídas ao longo do implante, fato este que promove maior estabilidade e menor risco de problemas mecânicos como o afrouxamento de parafusos ou fraturas na junção entre implante e pilar intermediário ${ }^{11}$. Quando ocorre, tais complicações podem acarretar em inflamação dos tecidos circundantes aos implantes, hiperplasia gengival, formação de fístula ou até mesmo prejudicar a osseointegracao ${ }^{12}$

Neste sentido, quando as conexões protéticas forem do tipo $\mathrm{HE}$ ou HI, comprovadamente com menor estabilidade mecânica quando comparada às conexões do tipo CM, sugere-se que o sistema de retenção deveria ter como característica a reversibilidade, uma vez que o afrouxamento do componente protético é certamente previsível, ou seja, deve-se dar preferência ao uso da fixação por parafusamento ${ }^{11}$.

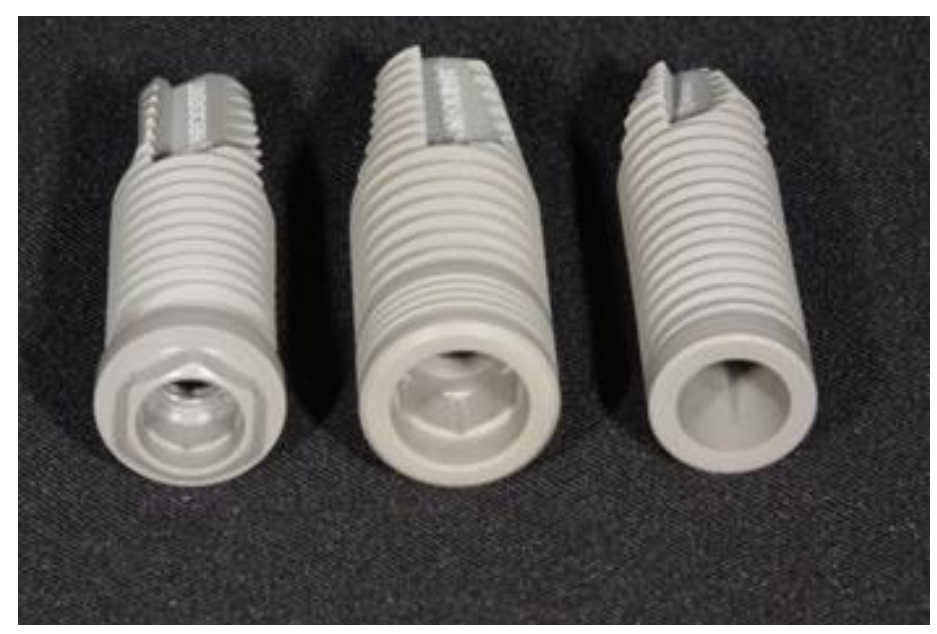

Figura 1: Imagem ilustrativa das três principais conexões protéticas (HE, HI e CM), demonstrando a profundidade de fixação da coroa protética sobre esses implantes-conexões protéticas. Note que no HE, a fixação fica às custas do hexágono externo que apresenta em média apenas $0,7 \mathrm{~mm}$ de altura; já no HI, essa fixação melhora um pouco com uma profundidade média de fixação de $1,8 \mathrm{~mm}$; já no $\mathrm{CM}$, a fixação é mecanicamente mais estável, apresentando em média $3,5 \mathrm{~mm}$ de profundidade.

Em relação à reversibilidade, trata-se de um princípio que, quando aplicado à reabilitação com implantes, permite a substituição regular dos componentes protéticos quando assim for necessário, higienização da peça protética, reajuste oclusal e repolimento, a substituição da peça protética em situações de condenação de implantes, as reintervenções cirúrgicas; sendo que, em situações de fratura ou intercorrências nos parafusos de fixação, o acesso e reparo ocorrem de forma mais simplificada ${ }^{13,14}$. Tal princípio é tratado por muitos autores e profissionais como uma característica inerente às próteses parafusadas, sugerindo que apenas esta modalidade de fixação pode ser removida ${ }^{15-19}$

De fato, as próteses parafusadas apresentam maior facilidade de remoção o que facilita o controle clínico quando são necessários reparos e manutenções. Além disto, esta característica possibilita especificamente nesta modalidade de fixação melhor higienização e proservação dos tecidos periimplantares ${ }^{20}$.

Sugere-se que o sistema de fixação à base de parafusamento seja aplicado principalmente nos casos de próteses múltiplas (próteses do tipo protocolo de Branemark ou próteses sobre implantes múltiplas acima de 02 elementos), pela probabilidade de ocorrência de alguma intercorrência na prótese que possa requerer sua remoção para reparo (caso de fratura da cerâmica odontológica, soltura do dente artificial de resina acrílica da prótese etc), como ilustrado nas Figuras 2 e 3.

No entanto, alguns autores afirmam que a reversibilidade não é uma vantagem específica das próteses parafusadas $^{6,9,16}$. Francischone et al. ${ }^{21}$ recomendam a 
utilização de cimentos provisórios na fixação das restaurações sobre implantes. Hebel e Gajjar ${ }^{6}$ corroboraram com este conceito e preconizaram a realização de preparos não cônicos e o emprego de cimentos provisórios para facilitar a remoção das próteses cimentadas. Além disso, Misch $^{9}$ afirmou que a remoção e reinserção das próteses cimentadas ocorrem de forma mais descomplicada do que nas próteses parafusadas, principalmente, quando os orifícios de acesso aos parafusos estão restaurados. Neste sentido, o tipo de fixação da prótese sobre o implante deve ser definido previamente ao ato cirúrgico, uma vez que a escolha de alguma destas opções pode interferir no posicionamento dos implantes, principalmente em regiões estéticas ${ }^{9}$. Contudo, esta decisão é mais complexa e não deve ser analisada apenas sob o ponto de vista de um critério de seleção.

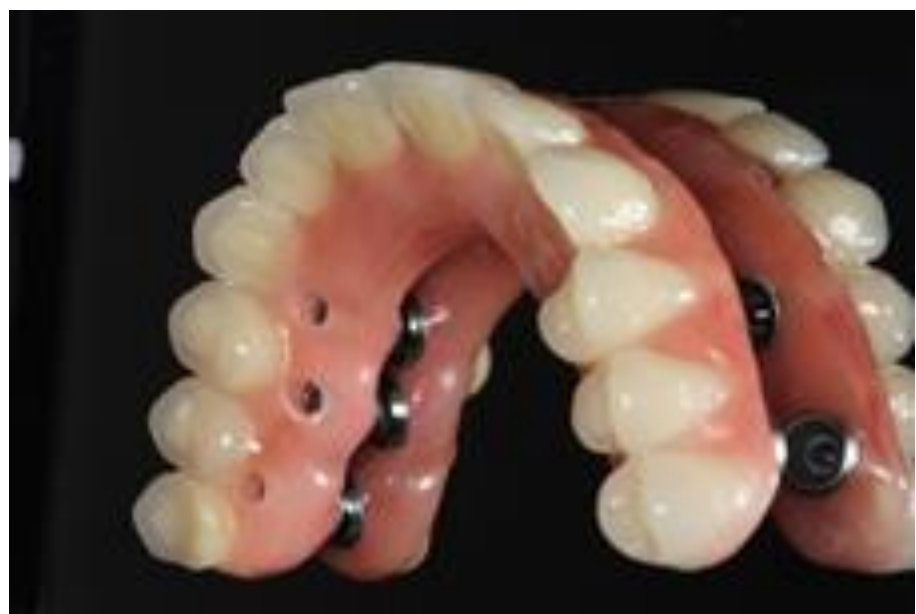

Figura 2: Exemplo de prótese com fixação por parafusamento: prótese do tipo protocolo de Branemark, cuja fixação por parafusamento permite a manutenção adequada dessa prótese quer seja para higienização ou para reparo.

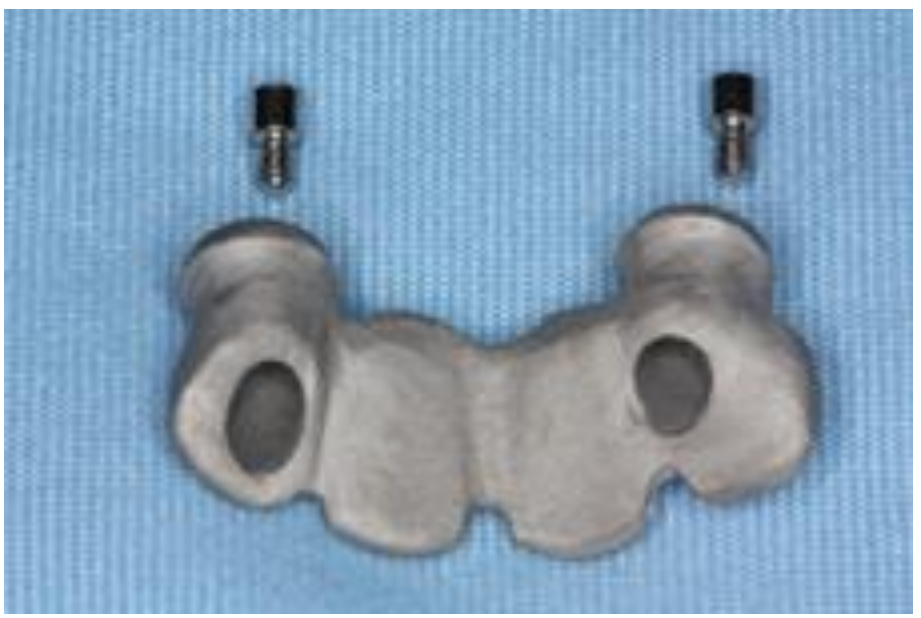

Figura 3: Infraestrutura metálica de uma prótese sobre implante múltipla de 04 dentes $(11,12,21$ e 22), cujo sistema de fixação escolhido foi o de parafusamento, favorável nessa situação pois a entrada dos parafusos ocorre pela face palatina, não interferindo na estética final da prótese.

A confecção das próteses sobre implantes passa por inúmeras etapas e proporcionalmente inúmeras são as distorções que podem ser acumuladas até a entrega da peça final. Segundo Michalakis et al. ${ }^{14} \mathrm{o}$ conceito de adaptação passiva da peça protética ao implante só pode ser implementado quando a somatória das distorções durante o processo de confecção da prótese for equivalente a zero. Diz-se por adaptação passiva quando a estrutura metálica implantossuportada se adapta com o mínimo de desajuste marginal e com a ausência de transmissão de tensões em proporções não fisiológicas ao osso alveolar ${ }^{21,22}$. Quando esta passividade não é alcançada, a transferências destas tensões ao osso ocorre de forma exacerbada e pode ter consequências desastrosas como a instauração do processo de saucerização, possível perda da osseointegração e desenvolvimento de periimplantite, além de fratura do parafuso de fixação ou do implante ${ }^{14}$

Segundo Hamata et al. ${ }^{23}$ a falta de adaptação pode ser a resultante multifatorial de um ou mais erros que podem ocorrer durante a moldagem realizada sob técnica inadequada, devido a distorções inerentes a qualidade e seleção errônea dos materiais de moldagem utilizados, ao processo de fabricação das estruturas metálicas incluindo o processo de soldagem e a aplicação da porcelana sobre esta estrutura, necessitando de experiência dos profissionais envolvidos neste processo para a realização destes procedimentos e aferição da passividade (Figura 4).

Certamente, considerando o acontecimento destas falhas e a impossibilidade de controle de todo o processo de confecção das próteses, parece utópico acreditar no alcance integral da passividade e adaptação dentro da limitação instituída por Branemark $(10 \mu \mathrm{m})^{5}$. Para minimizar estes desajustes, o emprego da técnica adequada de moldagem deve ser efetuado sob a utilização de materiais de moldagem mais fidedignos e com baixa deformidade elástica. A avaliação radiográfica da adaptação dos componentes de moldagem também é um fator preponderante para alcançar os resultados desejados. Cabe ao profissional determinar qual o nível clínico de passividade aceitável aplicável em sua rotina reabilitadora, utilizando-se de recursos clínicos como o teste do parafuso único e também tendo a percepção de passividade na inserção dos parafusos ${ }^{24,25}$.

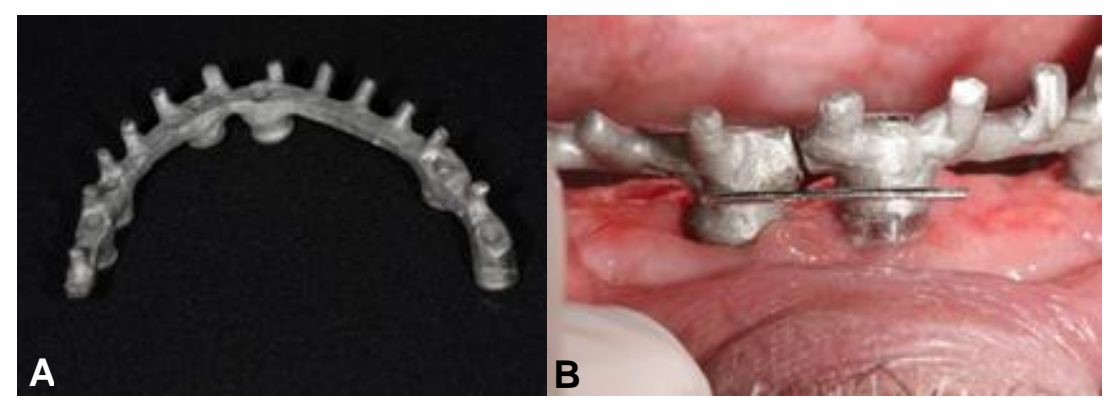

Figura 4: Ilustração de peça protética complexa e extensa (A), que apresentou dificuldade de assentamento passivo que pode ter ocorrido pelos processos laboratoriais e ou de moldagem, o que requereu o corte da peça para soldagem (B). A passividade pode ser notada pelo rosqueamento dos parafusos de forma passiva ou sem tensão.

Alguns autores consideram que as desadaptações das próteses fixadas por parafuso são expressamente irrelevantes quando comparadas aquelas fixadas por cimento $^{6,26}$. Guichet et al. ${ }^{18}$ em seu estudo avaliaram a desadaptação marginal e a passividade entre próteses parafusadas e cimentadas por meio de análise microscópica e fotoelástica e constataram uma desadaptação de aproximadamente $49,1 \mu \mathrm{m}$ nos casos de cimentação e de aproximadamente $16,5 \mu \mathrm{m}$ nos casos de parafusamento após a instalação das peças. Contudo, identifica-se que paralelo ao fato da confecção de uma prótese parafusada apresentar uma desadaptação marginal reduzida, esta modalidade provoca uma formação de tensões extras o que faz com que a ausência de passividade nesta modalidade seja ainda mais prejudicial resultando em deformidades mecânicas na interface coroa-pilar e aumento da concentração de forças nos implantes, uma vez que não há formação de espaço entre a coroa e o pilar passível de corrigir os desajustes nesta interface ${ }^{23,26}$. Devido ao selamento propiciado pelo cimento compensando o "gap" formado pela desadaptação coroa-pilar, as próteses cimentadas são reduzidamente prejudicadas por essas distorções quando comparadas as parafusadas, e soma-se a este fato a possibilidade de uso de agentes cimentantes resinosos - cimentos resinosos, que notadamente apresentam menos solubilidade em relação aos cimentos convencionais à base de fosfato de zinco e 
ionômero de vidro ${ }^{23,26}$.

A desadaptação da prótese sobre o pilar forma um espaço que não pode ser corrigido nas próteses parafusadas pela ausência da película de cimento possibilitando assim a colonização de bactérias patogênicas aos tecidos periimplantares. No entanto, quando os profissionais fizerem o uso do sistema de cimentação, é importante considerar que a solubilidade do cimento pode resultar na criação de novos espaços e acarretar o mesmo problema ${ }^{27}$. No entanto, a instalação das próteses parafusada requer uma menor manipulação dos tecidos moles periimplantares já que não requer a remoção dos excessos de cimento na porção subgengival, como ocorre nas próteses cimentadas. Quando não completamente removido, este excesso no interior do sulco periimplantar propicia maior acúmulo de placa e consequentemente maior inflamação da gengiva circunjacente ${ }^{23,26}$.

Dumbrigue et al. $^{28}$ recomendaram a técnica de cimentação denominada "practice abutment" na qual a coroa protética completamente preenchida com cimento é colocada anteriormente sobre uma peça análoga ao pilar com intuito de diminuir significativamente os excessos do cimento utilizado e proporcionar um selamento marginal ótimo.

Rajan e Gunaseelan ${ }^{26}$ recomendaram, com o intuito de atenuar esta situação, que a inserção do cimento ocorra apenas na porção oclusal da prótese. Misch ${ }^{9}$ preconizou que o término da coroa, sempre que assim for possível, se mantenha supragengival e que o uso de fio retrator no sulco implantar abaixo da margem seja protocolado principalmente precedente á cimentação com cimentos mais consistentes.

As diretrizes de retenção e estabilidade que norteiam a cimentação das próteses fixas convencionais dentossuportadas são igualmente aplicáveis às próteses implantossuportadas cimentadas ${ }^{18,23,27}$. Esta fixação pode ocorrer por meio de cimentos definitivos ou provisórios. Os cimentos definitivos são aqueles utilizados com intuito de potencializar a retenção e promover selamento marginal ótimo. Os cimentos provisórios, por sua vez, são utilizados naqueles casos em que se deseja facilidade de remoção da restauração e seu emprego só é possibilitado devido ao fato dos pilares possuírem área superficial maior do que a maioria dos dentes naturais ${ }^{14}$. Misch ${ }^{9}$ afirmou que o emprego de pilar em titânio polido com ausência de retenções pode comprometer a adesão dos cimentos, necessitando por isso do emprego de um cimento de consistência mais dura. Schlikmann ${ }^{29}$ preconizou a técnica da cimentação progressiva, na qual a capacidade de adesão e a consistência do cimento empregado são aumentadas progressivamente até que se obtenha a retenção almejada.

Para que a efetividade da retenção por cimento ocorra de forma segura é necessário que haja o suporte de preparos com paredes longas e paralelas tanto quanto possível, seguindo-se os mesmos princípios dos preparos dentários com finalidade protética ${ }^{22}$. Por isso, nas situações em que o espaço interoclusal é diminuído, o emprego das próteses parafusadas é recomendado, já que seus pilares não exigem grandes alturas ${ }^{18,27,30}$. Segundo Misch ${ }^{9}$ a retenção de uma prótese parafusada ocorre em uma área menor porque seu componente vertical não precisa necessariamente ter $5 \mathrm{~mm}$ como é requerido pelas próteses cimentadas.

A fixação por cimento deve ser a escolha primária nas reabilitações em espaços edêntulos posteriores, uma vez que a obtenção de passividade no assentamento desta modalidade ocorre com maior facilidade e por sua instalação ser similar aqueles procedimentos adotados em próteses dentossuportadas ${ }^{9}$. Contudo, nos casos em que o espaço intermaxilar é reduzido, o sistema de retenção por parafuso se apresenta mais resistente às forças oclusais quando comparado ao uso de cimento. Porém, é importante considerar que neste espaço reduzido o manejo da chave do parafuso será dificultado, ${ }^{9,14}$.

Próteses cimentadas possuem superfícies oclusais íntegras e esta característica implica em um direcionamento facilitado das forças oclusais ao longo eixo do implante, já que os contatos oclusais ocorrem diretamente sobre a coroa e não sobre o material restaurador de obliteração do orifício de acesso aos parafusos, como ocorre nas restaurações parafusadas (Figuras 5 a 7$)^{8}$.

Hebel e Gajjar $^{6}$ afirmaram que estes orifícios medem cerca de $3 \mathrm{~mm}$ de diâmetro e comparando tal diâmetro ao diâmetro total da mesa oclusal do segundo pré-molar inferior, que corresponde ao valor de $5,5 \mathrm{~mm}$, este orifício ocupa cerca de $55 \%$ de toda a superfície oclusal. Neste sentido, a maior parte dos contatos oclusais ocorre diretamente sobre a resina composta, que é o material mais comumente utilizado para o fechamento deste orifício. Tal material não possui resistência apropriada e seu desgaste ocorre mais rapidamente quando comparado à porcelana $^{9,18,23}$.

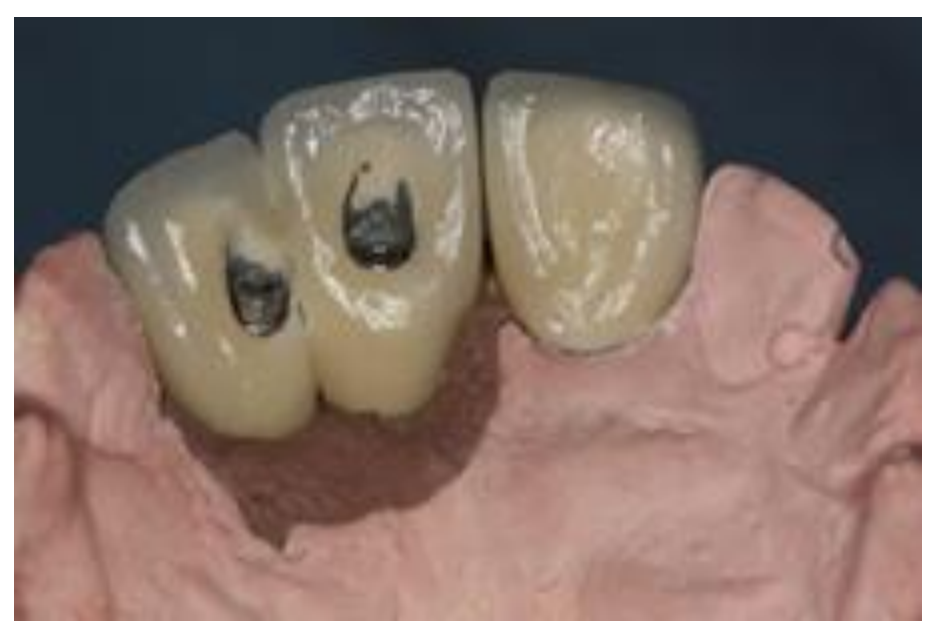

Figura 5: Ilustração de peça protética anterior com face palatina comprometida pelo orifício que permitirá a passagem dos parafusos de fixação. Esse fato deve ser previamente explicado ao paciente sobre pena de não aquiescência do mesmo.

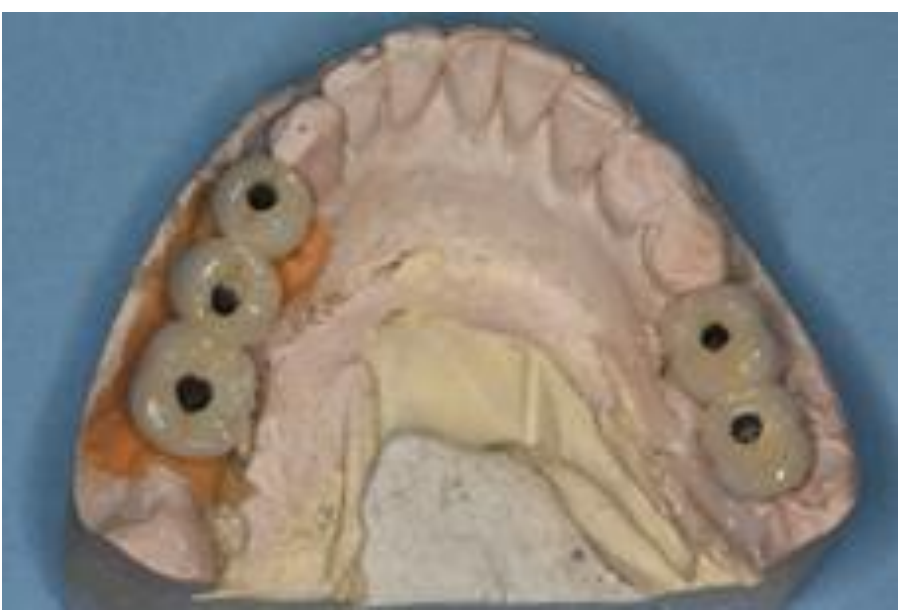

Figura 6: Ilustração de peça protética posterior com face oclusal comprometida pelo orifício que permitirá a passagem dos parafusos de fixação. Esse fato deve ser previamente explicado ao paciente sobre pena de não aquiescência do mesmo.

Com intuito de sanar tal problema, alguns autores descreveram técnicas com uma ampla variação de materiais para o vedamento destes orifícios; mas seu desempenho não se compara ao alcançado pelas superfícies intactas de porcelana ${ }^{9,30}$. Além disto, o uso da resina provoca uma modificação no designer da prótese, e no caso dos caninos e incisivos centrais, essa modificação da anatomia pode acarretar em interferências nos movimentos protrusivos, podendo comprometer a guia anterior ${ }^{6}$. Nas próteses 
cimentadas o centro da mesa oclusal possibilita que as forças axiais sejam geradas, transmitidas e melhor absorvidas pela interface osso-implante. Além disso, nas reabilitações em segmentos anteriores, as peças são confeccionadas com região palatina inteiriça e sem sobre contornos, o que permite que os movimentos excursivos da mandíbula sejam realizados sem qualquer interferência ${ }^{22}$.

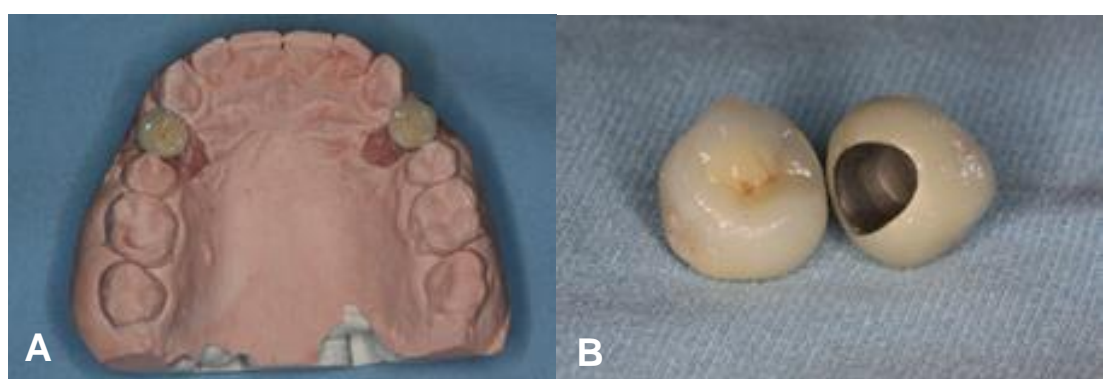

Figura 7: Ilustração de peças protéticas de dentes posteriores que serão cimentadas sobre os pilares intermediários do tipo munhão universal (Munhão Universal Cone Morse 3.3x4x1.5, Neodent, Curitiba - PR). Note em A e B a integridade da face oclusal que trará rigidez estrutural para a coroa protética, além de melhor harmonia estética.

É unânime entre os autores que possivelmente a estética seja a característica mais vantajosa das restaurações cimentadas, uma vez que a abertura de acesso aos parafusos não são necessárias (Figura 7), permitindo uma alta performance por parte dos técnicos na elaboração do "designer" destas peças $5,7,8,9,26$. Esta modalidade ainda apresenta possibilidade de adaptação da coroa, nos casos em que o posicionamento dos implantes não ocorreu da forma desejada, possibilitando a correção da angulação dos mesmos sem prejuízo a estética na região cervical como ocorre quando do uso de pilares angulados na retenção por parafuso (Figuras 8 e 9$)^{22}$.

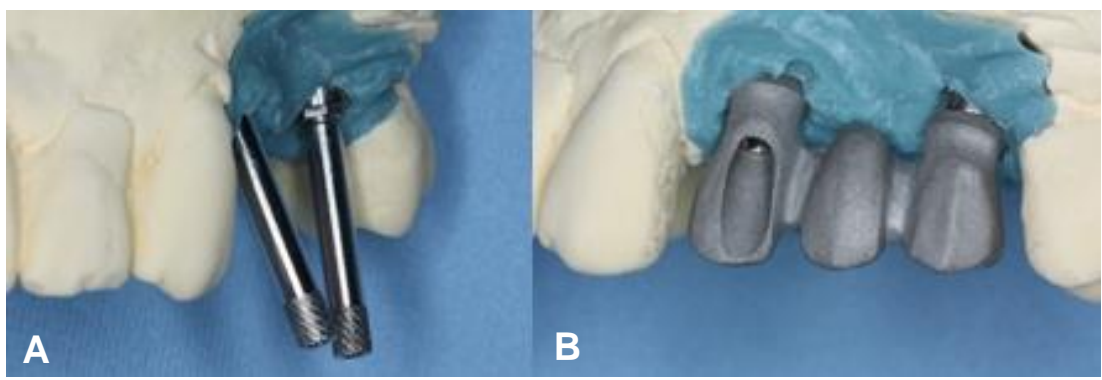

Figura 8: Posicionamento do implante da região do dente $23 \mathrm{com}$ inclinação para vestibular (A), ou seja, caso o parafusamento ocorra pela face vestibular, a cerâmica de cobertura ficará aberta na face vestibular para permitir o acesso ao parafusamento (B). Essa situação deve ser comunicada ao paciente e a decisão deve ocorrer em conjunto, considerando o tipo de implante instalado (qual a conexão), a posição apicocoronal do implante e quantidade de gengiva para a colocação de um pilar angulado (pois estes pilares exigem a presença de tecido gengival para esconder a margem do término cervical do componente).

Além disso, é possível a manipulação do perfil de emergência e do posicionamento do término da coroa de acordo com a anatomia das margens gengivais ${ }^{18}$. Quando a situação clínica determinar o uso da retenção por parafuso na região anterior devido a priorização de outros requisitos, os implantes devem ser instalados de forma mais palatinizada devido ao orifício de acesso ao parafuso estar localizado na região de cíngulo? .

O posicionamento incorreto dos implantes pode ocorrer nos sentidos vestibulolingual, mesiodistal e até coronoapical, e para cada situação clínica, o profissional deverá avaliar outros aspectos como presença de tecido gengival adequada, linha de sorriso do paciente e espaço interoclusal existente para então fazer a melhor opção pelo pilar intermediário e consequente sistema de fixação protética. $\mathrm{O}$ uso dos pilares angulados pode ser uma solução viável desde que haja um posicionamento apical adequado do implante, ou seja, que haja altura de tecido gengival adequada para esconder o término cervical do pilar intermediário, pois para a correção de angulação do implante, esses pilares tem um "joelho" que deixará o caso antiestético, principalmente se o paciente apresentar linha de sorriso alta (Figura 10).

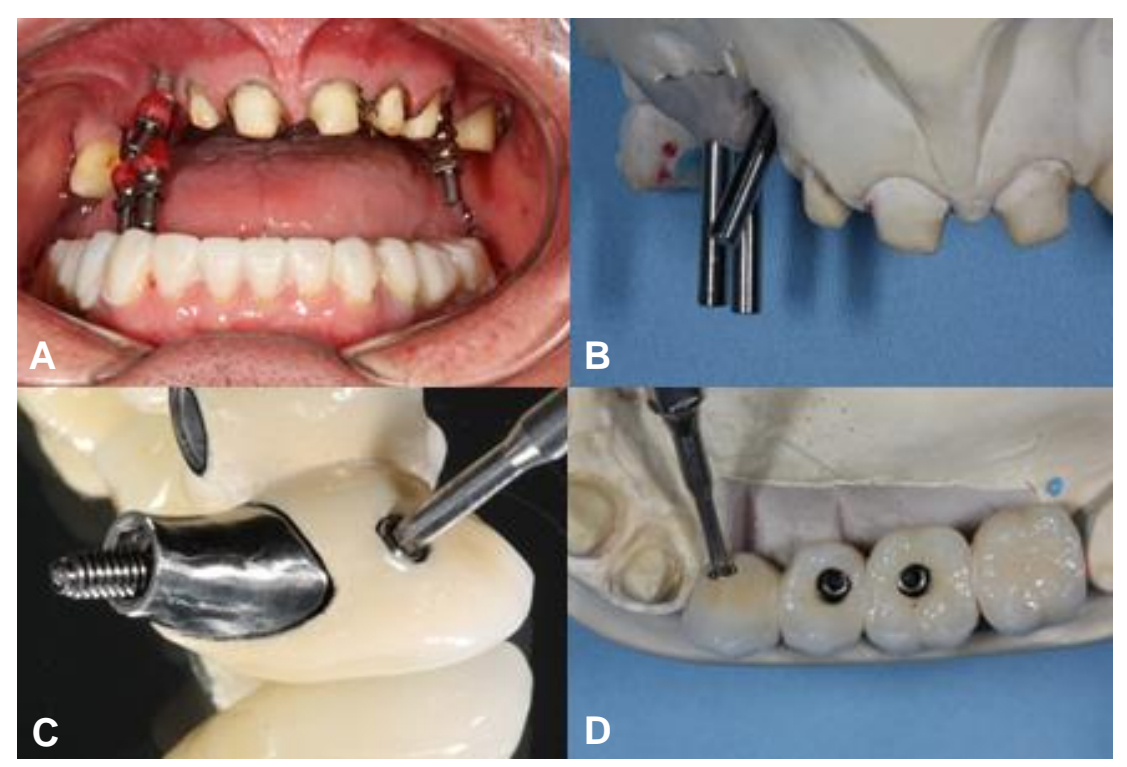

Figura 9: Aspecto clínico vestibular dos transferentes com mau posicionamento do implante da região do dente 13 (A) e confirmado no modelo de gesso com o posicionamento dos parafusos dos transferentes de moldagem (B). Nesse caso, ao invés de optar pelo uso de pilares angulados, optou-se pelo sistema de fixação chamado de tubo-parafuso, em que é confeccionado um pilar personalizado que será parafuso pela face vestibular nos implantes (C) e uma infraestrutura sobre esse pilar com parafusamento pela face palatina (D) e corrigindo dessa forma a angulação incorreta do implante, uma vez que o paciente não optou pela remoção do mesmo.

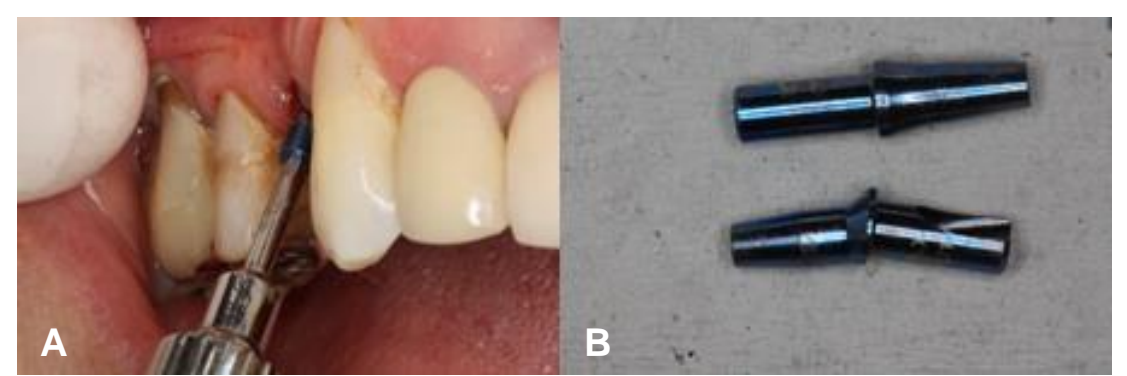

Figura 10: Ilustração de um posicionamento vestibular do implante, planejado previamente para o paciente "fugir" do procedimento de enxerto ósseo (A) e nesse caso, o foi necessário aprofundar apicalmente o implante, permitindo a futura colocação de um pilar intermediário angulado (B) e que não fosse atrapalhar esteticamente a resolução clínica do caso.

Normalmente os erros de posicionamento dos implantes ocorrem pela face vestibular, mas também poderão ocorrer pela face lingual ou palatina que também irão gerar transtornos aos pacientes, principalmente de sobrecontorno da peça protética, podendo inclusive alterar o posicionamento da língua, causando desconforto e até atrapalhar na função fonética (Figura 11).

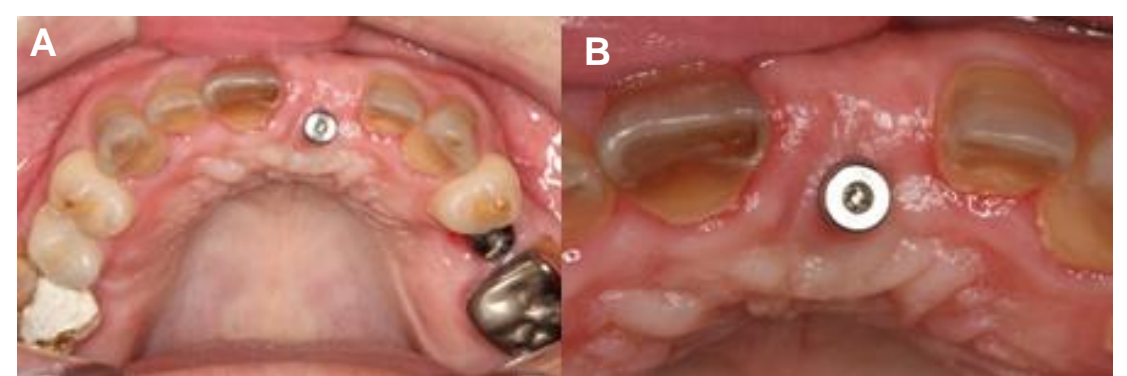

Figura 11: Aspecto oclusal de um implante com posicionamento palatino (A e B), que trará transtornos fonéticos e de sobrecontorno ao paciente. Nesses casos extremos, sugerir a explantação do implante pode ser uma opção.

Outro aspecto importante e digno de nota pelos profissionais é a personalização dos pilares em tecnologia CAD-CAM - odontologia digital, que possibilita a obtenção de pilares intermediários em material não metálico, ou seja, entre inúmeros materiais "metal free" destaca-se a zircônia, 
que por ter coloração branca, favorece e muito a obtenção de estética e nos casos de biótipo gengival delgado, a sombra acinzentada não trará prejuízos estéticos ao caso clínico, principalmente de regiões anteriores (Figura 12).

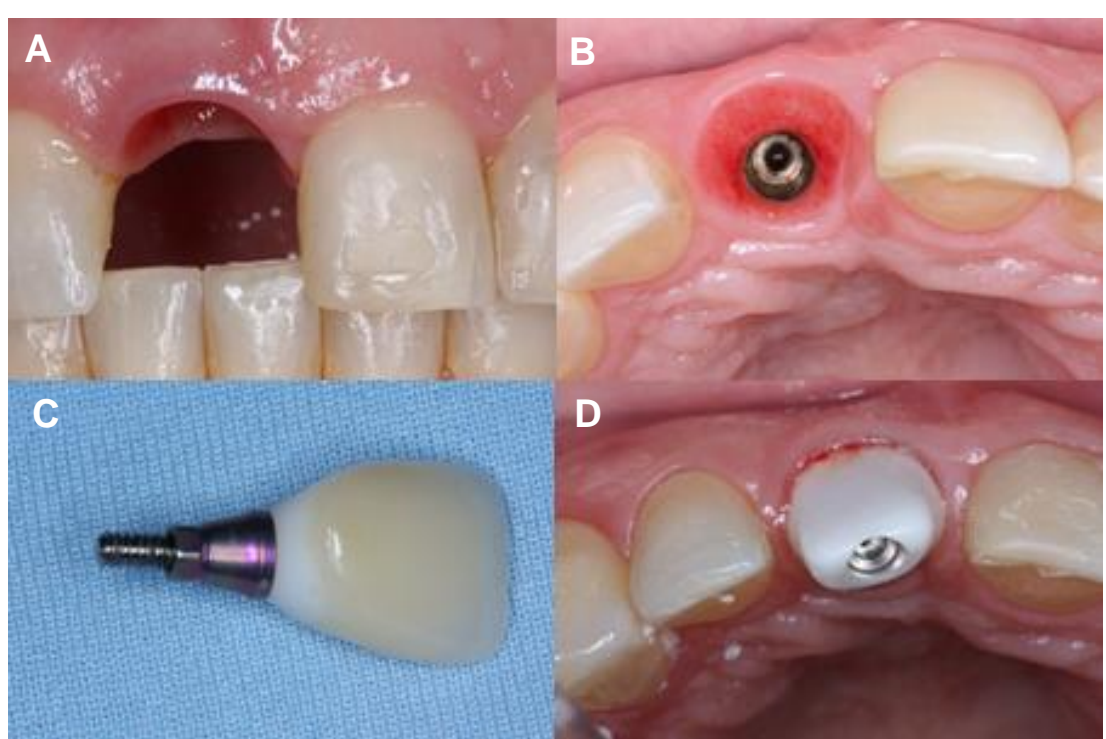

Figura 12: Ilustração de peça protética anterior na região do dente 11 (A) em que foi selecionado a personalização do pilar intermediário em tecnologia CAD-CAM. Note que apesar do correto posicionamento do implante e do biótipo gengival favorável (B), optou-se pelo uso do pilar em zircônia sobre uma base de titânio (conhecida como Ti-base, C), o que irá favorecer e muito no resultado estético (D). Note que o tecido gengival recebe muito bem esse material e não causa acinzentamento da margem gengival, fato este conhecido na literatura como sombra em formato de cabo de guarda-chuva.

Cimentar ou parafusar uma prótese sobre implante ainda irá gerar inúmeras dúvidas. No entanto, outros fatores associados aos casos clínicos que se apresentam devem ser considerados e irão convergir para a seleção pelo profissional:

- tipo de implante e consequente conexão protética (HE, $\mathrm{HI}$ ou $\mathrm{CM}$ );

- tipo de prótese sobre implante, se unitária ou múltipla;

- cuidados com o assentamento passivo da peça protética;

- necessidade de integridade ou não da superfície oclusal e ou lingual/palatina;

- posicionamento vestíbulo-lingual, mésio-distal ou corono-apical dos implantes;

- uso ou não de pilares angulados;

- espaço interoclusal presente;

- presença ou não de tecido gengival e seu biótipo;

- posicionamento da linha do sorriso, se alta, média ou baixa;

- pilar intermediário escolhido, se direto na "cabeça" do implante ou sobre algum pilar intermediário, ou até mesmo se personalizado em tecnologia CAD-CAM;

- filosofia de cada profissional, que implica na sua escola de formação em prótese e implantodontia, e de sua curva de aprendizado e evolução.

\section{CONSIDERAÇÕES FINAIS}

Ao final deste trabalho foi possível traçar as seguintes considerações:

- As próteses sobre implantes fixadas por parafusos têm como principais vantagens a reversibilidade; requerimento de menor espaço interoclusal e facilidade de remoção quando necessário para manutenção e reparos na própria peça ou no implante em si. Contudo, o seu emprego exige maior precisão operatória no momento de instalação do implante, uma vez que deve ser analisado o posicionamento do orifício de acesso ao parafuso de fixação. Além disso, seu processo de fabricação é tecnicamente mais delicado, devendo o profissional estar atento à adaptação passiva das peças protéticas. Em adição, quando o profissional se deparar com conexões protéticas com menos estabilidade mecânica como o HE e HI, recomenda-se o uso de sistema por parafusamento.

- A confecção de peças cimentadas sobre implantes remete aos conceitos das próteses fixas dentárias convencionais, não é tecnicamente tão exigente e, portanto, seu custo é reduzido em comparação às próteses parafusadas. Outras vantagens deste tipo de retenção incluem a compensação de discrepâncias no posicionamento do implante, a passividade no assentamento, estética favorecida e ajuste oclusal facilitado. Sua principal desvantagem consiste na dificuldade em remover os excessos de cimento na porção subgengival, o que está diretamente associado ao desenvolvimento de doenças periodontais como a periimplante e a mucosite. Recomendase o uso das próteses cimentadas em situações de conexões protéticas mais estáveis mecanicamente como nos implantes do tipo CM, assim como em implantes mal posicionados que impeçam o parafusamento pelo cíngulo ou face oclusal.

- Diante do exposto, as duas modalidades reabilitadoras são passíveis de utilização e seu emprego pode ser promissor a depender da situação clínica. Cabe ao profissional, experiência e bom senso para pontuar quais características serão prioritariamente necessárias de serem sanadas objetivando longevidade da reabilitação, e então eleger o sistema de retenção que melhor atende suas expectativas. Não há a existência de um método soberano nem de um protocolo fixo e a predileção do profissional acaba por ser o fator determinante nesta escolha.

\section{REFERÊNCIAS}

1. Tagliareni JM, Clarkson E. Basic concepts and techniques of dental implants. Dent Clin North Am. $2015 ; 255-64$.

2. Neves FD, Oliveira MRS, Fernandes-Neto AJ, Lima JHF. Seleção de intermediários para implantes Branemark - compatíveis - Parte I: casos de implantes múltiplos. BCI. 2000; 7(25):6-19.

3. Pastor FP, Bellini DH, Motta MC, Mazini Neto P, Velasco AF. Assentamento Passivo em Próteses Retidas por Cimento: Relato de Caso Clínico. 3i Innov J. 1999; 3(1):39-42.

4. Taylor TD, Agar JR, Vongiatzi T. Implant prosthodontics: Current perpective and future direction. Int J Oral Maxillofac Implants. 2000; 15(1):66-75.

5. Dinato JC, Polido WD. Implantes osseointegrados: cirurgia e protese. São Paulo: Artes Médicas, 2004

6. Hebel KS, Gajjar RC. Cement-retained versus screwretained implant restoration: Achieving optimal occlusion and esthetics implant dentistry. J Prosthet Dent. 1997; 77(1):28-34.

7. Freitas $\mathrm{R}_{2}$ Oliveira $\mathrm{JLG}_{2}$ Almeida $\mathrm{AA}_{2}$ Maia BGF. Parafusar ou cimentar: qual a melhor opção para as próteses implanto-suportadas? ImplantNews. 2007; 4(3):255-60.

8. Almeida EO, Freitas Júnior AC, Pellizzer EP. Restaurações cimentadas versus parafusadas: parâmetros para seleção em prótese sobre implante. Innov Implant J. 2006; 1(1):15-20.

9. Misch CE. Implantes Dentários contemporâneos. 3. ed. Santos: São Paulo; 2006.

10. Wittneben JG, Millen C, Brägger U. Clinical performance of screw-versus cement-retained fixed implant-supported reconstructions a systematic review. Int J Oral Maxillofac Implants. 2014; 29 (Suppl):84-98. 
11. Zavanelli RA, Magalhaes JB, Paula WN, Zavanelli AC. Critérios e orientações para a seleção de pilares intermediários em implantodontia. Artmed Panamericana: Porto Alegre; 2015.

12. Shin HM, Huh JB, Yun MJ, Jeon YC, Chang BM, Jeong CM. Influence of the implant-abutment connection design and diameter on the screw joint stability. J Adv Prosthodont. 2014; 6(2):126-32.

13. Chiche, GJ, Pinault A. Considerations For Fabrication Of Implant-Supported Posterior Restorations. Int $\mathrm{J}$ Prosthodont. 1991; 4(1):37-44.

14. Michalakis KX, Hirayama H, Garefis PD. Cementretained versus screw-retained restorations: a critical review. Int J Oral Maxillofac Implants. 2003; 18(5): 719-28.

15. Agar JR, Cameron M, Hughbanks JC, Parker MH. Cement removal from restorations luted to titanium abutments with simulated subgingival margins. J Prosthet Dent. 1997; 78(1):43-7.

16. Chee W, Felton DA, Johnson PF, Sullivan DY. Cemented versus screw retained implant prostheses. Which is better? Int J Oral Maxillofac Implants. 1999; 14(1):137-41.

17. Fernandes Neto AJ, Neves FD, Prado CJ. Prótese Implantada Cimentada versus parafusada: a importância da seleção do intermediário. Robrac. 2002; 11(31):22-6.

18. Guichet DL, Caputo AA, Choi H, Sorensen JA. Passivity of Fit and Marginal Opening in Screw- or Cement-Retained Implant Fixed Partial Denture Designs. Int J Oral Maxillofac Implants. 2000; 15(2):239-46.

19. Keith SE, Miller BH, Hoody RD, Higginbottom FL. Marginal Discrepancy of Screw-Retained and Cemented Metal Ceramic Crowns on Implants Abutments. Int J Oral Maxillofac Implants. 1999; 14(3):369-78.

20. Freitas RD, Oliveira JLGD, Almeida Junior AAD, Maia BGF. Parafusar ou cimentar: qual a melhor opção para as próteses implanto-suportadas? ImplantNews. 2007; 4(3):255-60.

21. Francischone CE, Ishikiriama SK, Vasconcelos LW. Próteses parafusadas $\mathrm{X}$ próteses cimentadas sobre implantes osseointegrados: vantagens e desvantagens. Rio de Janeiro: Pedro Primeiro; 1999.

22. Zarone F, Sorrentino R, Trainic T, Di lorio D, Caputo S. Fracture resistance of implant supported screw versus cement retained porcelain fused to metal single Crowns Sem Fractographic Analysis. Dent Mater. 2007; 23(3):296-301.

23. Hamata MM, Zuim PRJ, Rocha EP, Asuncao WG. Adaptação Passiva Em Implantes Osseointegrados. Rev Bras Implantodont Prótese Implant. 2005; 12(47/48):228- 35.

24. Herbst D, Nel JC, Driessen CH, Becker PJ. Evaluation of impression accuracy for osseointegrated implant supported superstructures. J Prosthet Dent. 2000; 83(5): $555-61$.

25. Hussaini S, Wong T. One clinical visit a multiple implant restoration master cast fabrication. J Prosthet Dent. 1997; 78(6):550-3.

26. Rajan M, Gunaseelan R. Fabrication of a cement and srew-ratained implant protesis. J Prosthet Dent. 2004; 92(6):578-80.

27. Karl M, Rosch S, Graef F, Taylor T, Heckmann SM. Strain Situation after fi xation of three-unit ceramic veneered implant superstructures. Implant Dentistry. 2005; 14(2): 157-64.

28. Dumbrigue HB, Abanomi AA, Cheng LL. Techniques to minimize excess luting agent in cement-retained implant restorations. J Prosthet Dent. 2002;87(1):112-4.

29. Schlickmann S. Prótese parafusada versus prótese cimentada. Rev Catarin Implant. 2000; 1(1):54-6.

30. Weber HP, Kim DM, Ng MW, Hwang JW, Fiorellini JP. Periimplant soft-tissue health surrounding cementand screw-retained implant restorations: a multi-center, 3 year prospective study. Clin Oral Impl Res. 2006; $17(4): 375-9$

\section{CONFLITO DE INTERESSES}

Os autores declaram não haver conflitos de interesse.

\section{AUTOR PARA CORRESPONDÊNCIA}

Ricardo Alexandre Zavanelli

ricardozavanelli@hotmail.com

Submetido em 06/10/2017 Aceito em 09/11/2017 